\title{
So much for percentage, but what about the weight?
}

\section{T C S Cubison, P M Gilbert}

Emerg Med J 2005;22:643-645. doi: 10.1136/emj.2003.011304

The use of resuscitation formulae for burns is advocated for A\&E departments. Much care is taken to calculate the percentage of the burn, but this is then multiplied by an approximate weight. How accurate is this figure and should it be more carefully measured?

Forty two sets of case notes of patients with resuscitation sized burns were reviewed. In 32, a weight was documented in the A\&E notes. This was compared with the measured weight on arrival at the burn centre. In half the cases there was a greater than $5 \mathrm{~kg}$ difference and in nine patients over $10 \mathrm{~kg}$ of difference.

The methods of patient weight assessment in 16 A\&E departments were reviewed. The majority have only stand on scales. Three departments have sit on scales; however, if they were assessing the weight of a patient who is unable to sit they would need to ask the patient, relatives, or simply guess.

Investment in weighing equipment should be encouraged if resuscitation formulae are to have any place in the A\&E management of burn patients.

$\mathrm{T}$ he understanding of the need for intravenous fluid resuscitation and the adoption of resuscitation regimes is one of the significant issues that has improved the mortality of major burns over the last 50 years. ${ }^{1-3}$

Formulae have been established for crystalloid and colloid resuscitation, and the volumes suggested reflect the different properties of these fluids. The most common combinations are the Parkland formula for crystalloid resuscitation with Hartmanns solution and the Muir and Barclay formula for colloid resuscitation. ${ }^{45}$ The Muir and Barclay formula was originally described using plasma and is usually modified to reflect the fact that in current practice human albumin solution is used.

The resuscitation formulae provide a guideline for the commencement of intravenous fluid resuscitation, the effect of the regimen is judged by clinical indicators such as urine output, and patients must be continuously monitored then the actual volumes delivered adjusted accordingly.

The initial resuscitation plan is commenced in the referring accident and emergency department (A\&E) prior to the transfer of the patient to the burn centre and the use of formulae is therefore strongly recommended. The use of the Parkland formula and Hartmanns resuscitation is taught both by Emergency Management of Severe Burns (EMSB) and Advanced Trauma Life Support (ATLS) programmes. ${ }^{67}$

The main components of both formulae are the patient's total percentage body surface area burnt (\%TBSA) and their weight in kilograms. The \%TBSA can be assessed clinically using Lund and Browder burns charts ${ }^{8}$ or Wallace's rule of nines.

There has been considerable interest from the burns fraternity to educate A\&E staff in the rather subjective art of percentage assessment as a method of improving the accuracy of fluid resuscitation calculations. The weight measurement appears not to have been equally scrutinised.

Our hypothesis is that the assessment of weight of patients with burns in A\&E is an objective measurement.

\section{OBJECTIVE}

A study was undertaken to consider weight assessment by A\&E units. The aims were to establish the methods of weight assessment and to review the accuracy of this assessment in some resuscitation sized burns.

\section{MATERIALS AND METHODS}

The case notes of 42 patients who had sustained burns over $15 \%$ TBSA in adults and 10\%TBSA in children were obtained and their A\&E documentation reviewed. The A\&E weight was noted when available and this was compared with the weight assessed at the burn centre. The A\&E weight was subtracted from the burn centre weight and a difference in kilograms obtained

The burn centre weight is assessed using a weighbridge. On arrival the patient and trolley are weighed, and after the patient is transferred the trolley and all equipment are weighed again so that a fairly accurate subtraction weight is established.

Subsequently, all 16 local A\&E units were contacted by telephone and the staff were questioned:

1. How do you routinely weigh patients?

2. Do you have any way of weighing a patient unable to stand?

3. How do you assess the weight of a patient in your resuscitation room?

\section{RESULTS}

Forty two sets of case notes were obtained and 32 contained A\&E assessment of weight. The average age was 46 years (range 13-91) with only one paediatric patient. The average TBSA burnt was $37 \%$ (range $15-86 \%$ ).

In half of the patients there was a difference of over $5 \mathrm{~kg}$ between the A\&E weight and that of the burn centre, and in nine patients the difference was over $10 \mathrm{~kg}$ (fig 1 ).

In the telephone survey the 16 units questioned all routinely used a stand-on scale for adults. Three units had access to a sit on scale (not always in A\&E). No unit had an objective method of assessing patients in the resuscitation room (table 1). The normal practice is to ask the patient or relatives how much they weigh or simply to make a guess.

\section{DISCUSSION}

It is clear from this study that the assessment of weight in A\&E is not an objective measurement. The weights given are usually an underestimation, perhaps reflecting an underlying

Abbreviations: A\&E, accident and emergency; ATLS, Advanced Trauma Life Support; EMSB, Emergency Management of Severe Burns; TBSA, total percentage body surface area 


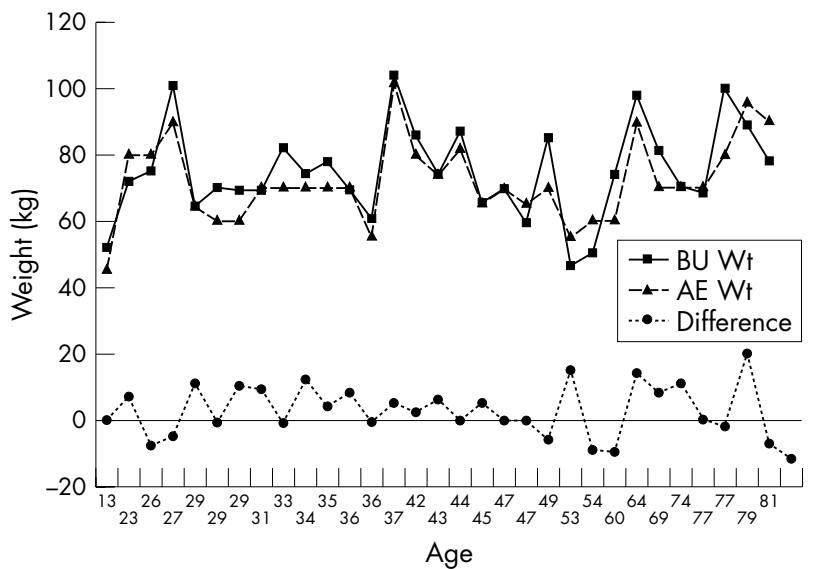

Figure 1 Individual patients' weights. $\mathrm{BU}$ wt should be Burn centre Weight in $\mathrm{kg}$; $A E$ wt is $A \& E$ weight in $\mathrm{kg}$; Difference is the difference between the Burn centre weight and A\&E weight.

wish to be lighter than we actually are. It is true that intravenous fluid resuscitation will be under way in transit and that the weight will increase by $1 \mathrm{~kg}$ per litre of fluid given; however, this does not account for discrepancies of over $5 \mathrm{~kg}$.

The practical implication of weight assessment needs to be considered in the context of a resuscitation formula and the maximum Parkland crystalloid formula of $4 \mathrm{mls} / \mathrm{kg} / \% \mathrm{TBSA}$ is used here.

To demonstrate the significance of a $10 \mathrm{~kg}$ weight discrepancy fig 2 plots increasing \%TBSA against calculated 24 hour fluid requirement, with columns representing increasing body mass within each \%TBSA.

This demonstrates that with increasing percentage burn a $10 \mathrm{~kg}$ weight discrepancy has more effect on the calculated volume. This is simplified in fig 3 where a standard $10 \mathrm{~kg}$ weight difference is shown with \%TBSA plotted against volume. The volume discrepancy can now be visualised more easily-for example, in a $75 \%$ burn, $10 \mathrm{~kg}$ of weight represents 3 litres of fluid over 24 hours.

The overall relevance must also consider the total weight of the patient for $10 \mathrm{~kg}$ is $12.5 \%$ of an $80 \mathrm{~kg}$ patient but $20 \%$ of a $50 \mathrm{~kg}$ patient. The lighter the patient the greater need for accuracy.
Table 1 Weighing equipment in accident and emergency departments

\begin{tabular}{lc}
\hline Weighing equipment & No of units \\
\hline Stand on scales & 16 \\
Sit on scales & 3 \\
Bed/trolley scale & 0 \\
\hline
\end{tabular}

Actual fluid volumes transfused were assessed; however, this figure does not simply reflect the patient weight estimation. The A\&E fluid calculation is based on their assessment of percentage (often different to the burn centre), and a delay from the time of injury may require a catch up period. The total volume transfused before reaching the burn centre also reflects the transfer time. These actual volumes were therefore not included but the following simplified calculations demonstrate the potential volumes involved.

In fig 4, the actual patient data for weight are used. To assess the impact of the weight discrepancy, the fluid requirements for each patient have been be calculated using the \%TBSA as assessed by the burn centre and the A\&E weight, which is then repeated using the burn centre

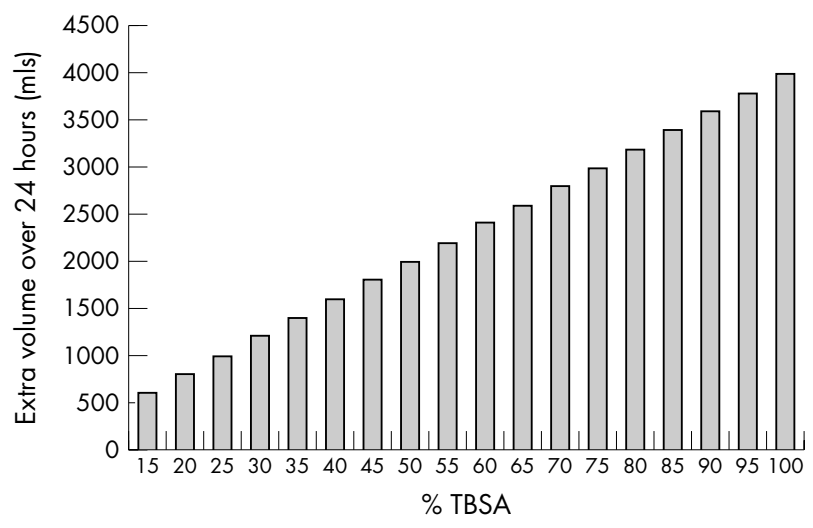

Figure 3 The influence of $10 \mathrm{~kg}$ weight estimation error. If the TSBA is $50 \%$, a $10 \mathrm{~kg}$ weight under estimation error would result in 2 litres less fluid calculated in the 24 hours resuscitation period.

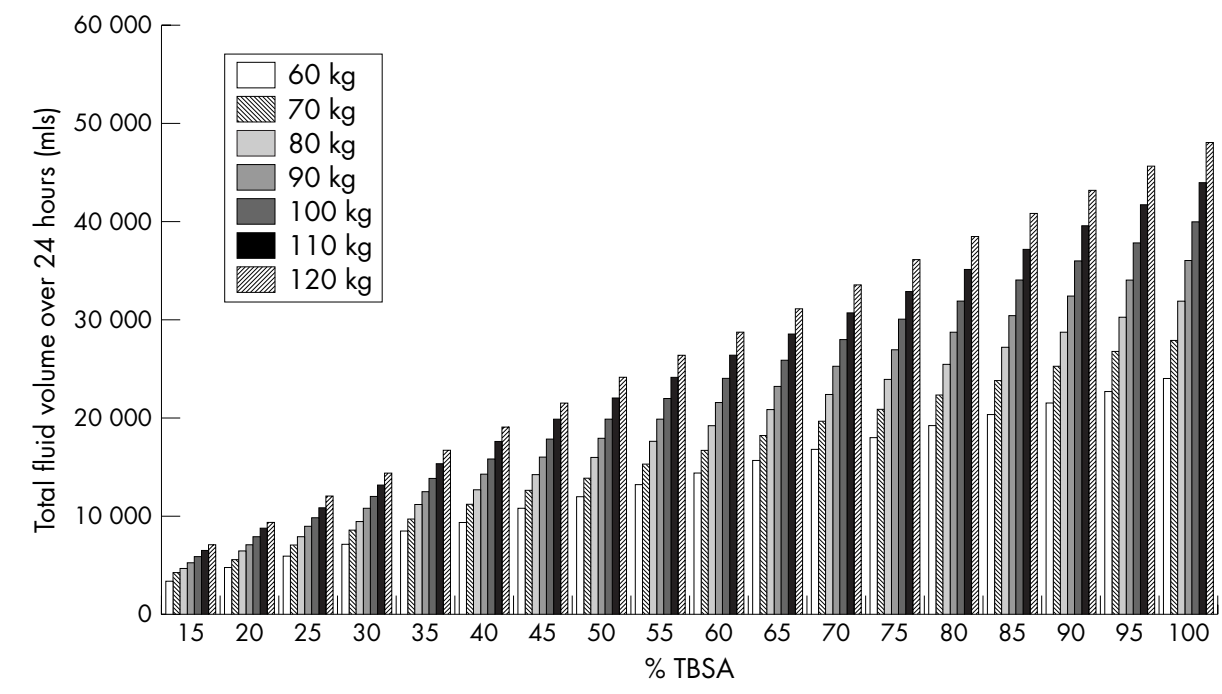

Figure 2 The influence of patient weight on Parkland Resuscitation volumes. 


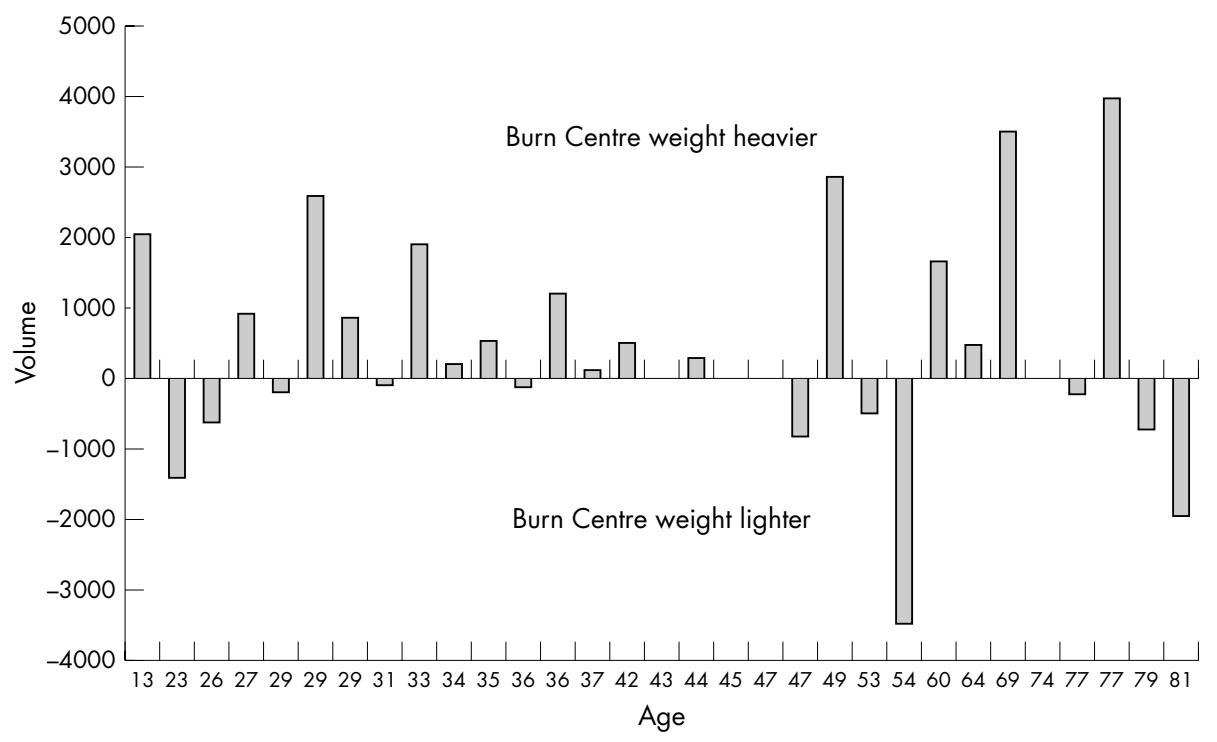

Figure 4 Calculated difference in fluid requirements over 24 hours.

percentage and burn centre weight and the two volumes compared.

The upper part of the chart represents patients who were assessed to be lighter by the A\&E and therefore prescribed insufficient fluid. These include a 77 year old patient who could have been under resuscitated by 4 litres. The lower part of the graph represents patients given more fluid than that required and these include a 81 year old patient given an extra 2 litres.

As previously mentioned, the formulae only provide a start point for resuscitation and should not be prescribed without adjustment for clinical assessments such as urine output; however, the formulae are effective when used carefully and this does include a good objective assessment of weight.

The measurement of weight can be achieved by the use of standard scales in a fit patient and the small \%TBSA patient may be able to sit on a suitable scale. The weighing of a recumbent patient does require more specialist equipment; however, this does not have to be of a prohibitively expensive nature. The options include a weigh bridge, specialist beds that contain integral weighing scales, and it is also possible to weigh the patient on the A\&E trolley using a specialist scale that clips around the trolley wheels.

The results from this study highlight the difficulty of weight assessment in the A\&E departments and have implications for many different specialties. If the patients' weight is documented inaccurately this may later be assumed to be an objective measurement and errors may occur. The availability of inexpensive trolley scales should be highlighted to those responsible for equipping A\&E departments as the problem of weight assessment inaccuracy is very easily solved.

\section{Authors' affiliations}

T C S Cubison, Specialist Registrar in Plastic Surgery

P M Gilbert, Consultant Plastic Surgeon and Director of the Mclndoe Burn Centre, Queen Victoria Hospital, East Grinstead, UK

Competing interests: none declared

Correspondence to: Tania Cubison, Slipmill Hollow, Hawkhurst, Kent TN18 5AB; tania.cubison@lineone.net

Accepted for publication 7 April 2004

\section{REFERENCES}

1 Jackson DM. Mclndoe lecture, 1978. Burns: Mclndoe's contribution and subsequent advances. Ann R Coll Surg Engl 1979;61:335-40.

2 el Danaf A. Burn variables influencing survival: a study of 144 patients. Burns 1995;21:517-20.

3 Fratianne RB, Brandt CP. Improved survival of adults with extensive burns. J Burn Care Rehabil 1997;18:347-51.

4 Muir IKF, Barclay TL. Burns and their treatment. London: Lloyd Luke Ltd, 1974.

5 Baxter CR. Fluid volume and electrolyte changes of the early postburn period. Clin Plast Surg 1974;1:693-703.

6 British Burn Association. Emergency Management of Severe Burns UK Course Manual, 1996.

7 Committee on Trauma American College of Surgeons. Advanced Trauma Life Support Course 1989.

8 Lund CC, Browder NC. Estimation of areas of burns. Surg Gyn Obst 1944;79:352-8. 